\section{AN INTRODUCTION TO SURGERY.}

By Rutherford Morison, M.D., F.R.C.S., \&c., Emeritus Professor of Surgery, Durham University, and Charles F. M. SaInT, C.B.E., M.D., F.R.C.S., Professor of Surgery, Cape Town University, South Africa. Third Edition. Bristol : John Wright \& Sons, Ltd. London: Simpkin, Marshall Ltd. 1935. Price, $15 /-$ net.

This work was originally written by Professor Morison "to aid the student in thinking out for himself the problems presented to him in the wards and in his textbooks." The object of this (third) edition remains the same, and its achievement is attempted through the consideration of general principles and their application. It is ten years since the second edition appeared, and the trifling increase in size - less than 20 pages-shows how closely the original scheme has been adhered to. Professor Saint's special contribution-a general scheme of the basis of the Principles of Surgery-forms Chapter I. It is marked here and there by slight amplifications to facilitate the student's grasping the principles set forth. This chapter is full of information; but the lettered sections and numbered paragraphs, and heavy type headings cause the text to be broken up, and consequently none too easily read or grasped by the student.

It is another matter when we come to deal with succeeding chapters. They are written by a master hand and bear the impress of close abservation and of wide experience, both in doing things and in describing them. The writer's practical advice to the reader crops up in many places throughout the work; and as a good example his remarks as to the value and wide applicability of the antiseptic method of wound treatment would be hard to beat.

The text is not unnecessarily voluminous, and it is helped by numerous illustrations of a high value. As regards them, we think Fig. 16 does not clearly show the passing of infection from the superior vena cava to the lungs by the pulmonary artery. Again, Fig. 66 apparently depicts a primary chancre of the upper, not lower lip.
The book is a good one, and will prove of great use not only to students, but also to surgeons who have advanced some way along the path of juniority. We have confidence in cordially recommending it.

\section{HIGH BLOOD PRESSURE AND ITS COMMON SEQUELE.}

By Hugh O. Gunewardene, M.B., B.S., D.M.R.E. Baillière, Tindall \& Cox. Pages 172. 1935. Price $7 / 6$ d.

The author, in his preface, states the aim of this book as being the encouragement of the general practitioner to study high blood pressure. In this aim it is likely to succeed, for it is a sane and stimulating account of a condition which confronts the practitioner every day. Dr. Gunewardene has been interested in the subject for many years both in London and Ceylon. $\mathrm{He}$ has made a particularly close study of 250 cases during the past seven years.

Of special interest are the author's records of certain special Cingalese classes of the community. Thus he found only one case of hypertension among 200 Buddhist priests, half of whom were over 50 years of age. $\mathrm{He}$ also found hypertension absent in elderly rickshawmen. Yet high blood pressure is stated generally to have a high incidence in Ceylon. He attaches much importance to heredity, over-eating, and under-exercise in the causation of non-renal hypertension.

The book is easy to read as its style is attractively discursive without being loose. It would be an advantage if the sources were specified of all work to which reference is made. Many references are quoted, but also many are left out. The book deserves the status of a monograph, and, as such, would be improved by more ample quotation of references. The author's poor opinion of venesection in the treatment of acute odema of the lungs in hypertension is unlikely to be shared by most clinicians.

It is to be hoped that Dr. Gunewardene will continue his careful clinical study of hypertension in Ceylon, and, that some day he will publish the results of his further experience in another edition of this commendable little book. 